\title{
Modern Natural Gas Development and Harm to Health: The Need for Proactive Public Health Policies
}

\author{
Madelon L. Finkel, ${ }^{1}$ Jake Hays, ${ }^{2}$ and Adam Law $^{3}$ \\ ${ }^{1}$ Department of Public Health, Weill Cornell Medical College, New York, NY 10065, USA \\ ${ }^{2}$ Physicians Scientists \& Engineers for Healthy Energy (PSE), 452 West 57th Street Apt 3E, New York, NY 10019, USA \\ ${ }^{3}$ Weill Cornell Medical College, Cayuga Medical Center, Ithaca, NY 14850, USA
}

Correspondence should be addressed to Jake Hays; hays@psehealthyenergy.org

Received 22 March 2013; Accepted 24 April 2013

Academic Editors: J. Konde-Lule, A. R. Mawson, and I. Szadkowska-Stanczyk

Copyright (C) 2013 Madelon L. Finkel et al. This is an open access article distributed under the Creative Commons Attribution License, which permits unrestricted use, distribution, and reproduction in any medium, provided the original work is properly cited.

\begin{abstract}
High-volume horizontal hydraulic fracturing of shale formations has the potential to make natural gas a significant, economical energy source, but the potential for harm to human health is often dismissed by proponents of this method. While adverse health outcomes of medical conditions with long latency periods will not be evident for years and will depend on the exposure, duration of exposure, dose, and other factors, we argue that it would be prudent to begin to track and monitor trends in the incidence and prevalence of diseases that already have been shown to be influenced by environmental agents. The dirty downside of modern, unconventional natural gas development, as well as the potential for harm, is discussed.
\end{abstract}

\section{Introduction}

A modern form of natural gas development has become a global "game changer" in the quest for energy. Natural gas, abundant around the world, has a clean reputation compared to other fossil fuels since it burns less carbon when used. It is easy to transport, reasonably economical, and requires comparatively quick construction timelines and low capital costs.

Traditionally, natural gas was extracted using a method that bores a vertical well in single gas reservoirs close to the surface (conventional natural gas drilling). However, drilling for natural gas in shale rock was not particularly economical, primarily because shale typically has insufficient permeability to allow significant fluid flow to a well bore. With technological advances and unconventional methods (i.e., horizontal hydraulic fracturing), gas extraction from tight formations (e.g., shale) is now feasible.

This type of unconventional natural gas development relies on clustered, multi-well pads and long, horizontal laterals. Wells are drilled vertically (often thousands of feet) and horizontally in multiple directions. The method entails injecting large volumes of fluid consisting of chemicals, water, and sand into the well to fracture the shale rock that releases the natural gas. The internal pressure of the rock formation also causes a portion of the injected fracking fluids to return to the surface (flowback fluids); these fluids are often stored in a tank or pit before being pumped into trucks for transport to a disposal site. Flowback has been shown to contain a variety of formation materials, including brines, heavy metals, radionuclides, and organics, which can make wastewater treatment difficult and expensive [1]. Further, other studies found that $20 \%$ to $85 \%$ of fracturing fluids may remain in the formation, which means the fluids could continue to be a source of groundwater contamination for years to come [2]. By 2009, there were more than 493,000 active natural gas wells across 31 states, almost double the number in 1990, of which approximately 90 percent have used hydraulic fracturing to extract gas [3].

Whereas shale gas has the potential to become a significant, economical energy source, the potential for harm and the potential of giving a false sense of energy security are often dismissed by its proponents. The process is potentially polluting and damaging not only to human and animal health but also to the environment, as a result of clearing of land for well pads, drilling the wells, extracting the gas, storing the byproducts of the extraction, transporting the gas by 
diesel trucks, and the final capping of the well. The potential for harm to children is especially worrisome. This paper focuses on a literature review of unconventional natural gas development and its potential impact on human health.

\section{Discussion}

Canaries in coal mines were used as an early-warning signal for toxic gases, primarily carbon monoxide. The birds, being more sensitive, would become sick before the miners thus providing advanced warning of a danger. Animals and children also can be viewed as sentinel species. A 1993 report, now viewed as a watershed moment for health and environmental policy, documented that children are more vulnerable and sensitive than adults to chemicals in the environment [4]. Early development (in utero and during the first few years after birth) is particularly sensitive to disruption by exposures to chemicals in the environment and to imbalanced nutrition, with potentially adverse consequences for health later in life [5]. A child's ability to metabolize toxic chemicals is different from an adult's. Children receive proportionately larger doses of chemical toxicants than adults, and these exposures occur at a time in the life cycle when organs and tissues are rapidly growing and developing.

Endocrine disrupting chemicals (EDCs) present a particularly concerning hazard during human growth and development. EDCs can affect the reproductive system and often effect epigenetic mechanisms leading to pathology decades after exposure. Given the potential for harm, it would be a prudent course of action that chemicals used in the hydraulic fracturing process be evaluated for their EDC potential and screening assays be developed to test flowback fluids.

Landrigan et al. [6], looking at children's vulnerability to toxic chemicals, found strong evidence that toxic chemicals are important causes of disease in children. For example, benzene, being toxic to all humans, has been shown to contribute a disproportionate risk of leukemia to young children [7]. Neural tube defects, spina bifida being the most common [8], and decreased fetal growth [9] also have been shown to occur disproportionately higher in children exposed to toxic chemicals, including benzene. Further, because of the long latency period of some diseases, toxic exposures in childhood are more likely to result in disease in adulthood compared to exposure in adulthood [10].

Trasande and Liu [11], building on Landrigan et al's analysis of the costs of environmental pollutants and disease [12], estimated that costs of environmentally mediated diseases in American children totaled $\$ 76.6$ billion (in 2008 dollars) and called for federal policy action to limit children's exposure to known chemical hazards, including exposures to toxic chemicals. Given the staggering human and economic costs of environmentally mediated diseases, a wise course of action would be to empirically document trends in specific diseases among children living in close proximity to unconventional natural gas operations compared to those living in areas where drilling is not occurring.

We acknowledge that adverse health outcomes of medical conditions with long latency periods will not be evident for years and will depend on the exposure, duration of exposure, dose, and other factors. A higher incidence of asthma, cancer, heart disease, and the effects of endocrine disruption on developing fetuses and children, due to contaminant exposure, only become evident over time. However, baseline measurements should be recorded and updated over time. As of this writing, the extent of health risks associated with unconventional natural gas operations among children is unknown.

In an effort to assess the impact of hydraulic fracturing on children's health, we are advocating that local and state governments work together to establish a system to track the incidence and prevalence of diseases that have been shown in the literature to be causally related or exacerbated by exposure to environmental agents. In Pennsylvania, for example, there has been active, on-going unconventional natural gas development since the late 2000s. There are currently 6,773 horizontal wells drilled or under development and over 9,600 drilling permits have been issued [13]. As of May 2011, 320 daycare facilities, 67 schools, and 9 hospitals were located within two miles of natural gas wells [14]. What effect will this activity have on the development of disease among children living in counties with active drilling as compared to children living in counties with little or no drilling activity? Trends in childhood cancers, especially acute lymphoblastic leukemia, birth outcomes including birth defects, premature and low birth weight births, neurodevelopment disorders, and, respiratory disease, especially asthma, should be monitored.

The limited information available on the chemicals that are used in the drilling hampers efforts to empirically assess the potential for harm. Oil and gas companies are legally permitted to withhold information on their proprietary mixtures, and the federal government has granted oil and gas companies exemption from many environmental law restrictions such as the Clean Water Act, Clean Air Act, Safe Drinking Water Act, Resource Conservation and Recovery Act, Toxic Release Inventory under Emergency Planning and Community Right-to-Know Act, and the National Environmental Policy Act. By default, states have the responsibility for enacting regulations; however, many states have weak or no regulations. As of February 2012, only four of 31 states have significant drilling rules; of these, 5 adopted disclosure rules, although they still allow for "proprietary trade secrets" [15].

\section{Harm to Health}

The production process creates a huge pressure cooker of organics and inorganics, and even if every single compound pumped into the well is harmless by itself (which is not the case), the pressure would create hundreds if not thousands of different compounds that are highly toxic. Of the few studies that have looked at the chemical cocktails used in the process, findings have identified chemicals that are known to cause cancers, mutations, and diseases of the nervous, immune, and endocrine systems, the kidney, gastrointestinal tract and liver, heart, and skin [16]. Colburn identified almost 1,000 chemical products and nearly 650 individual chemicals used in natural gas operations, many of which have the potential to cause adverse health effects as well as to potentially cause deleterious effects on the environment [17]. Specifically, the 
researchers documented that the hydraulic fracturing process releases toxic and cancer-causing chemicals such as benzene, toluene, xylene (BTEX), and methylene chloride among other health-hazardous air pollutants. These health-hazardous pollutants are released from a number of sources including blowouts, flaring, condensate tanks, construction activity, engines, and venting. Methane, a powerful greenhouse gas, also is emitted throughout the oil and gas development process. Methane interacts with sunlight to produce tropospheric ozone, which is a strong respiratory irritant associated with increased respiratory morbidity and mortality [18].

Witter et al. were one of the first to present a detailed assessment of health trends in Garfield County, CO, that documented the negative impact of drilling on air, soil, water, and human health [19]. Building on those findings, McKenzie et al. estimated health risks for exposures to air emissions from a natural gas development project also in Garfield County and found that residents living less than one-half mile away from wells were at greater risk for ill health effects than those living farther away [20]. Although these studies focused on Garfield County, CO, the researchers maintain that the exposure pathways and related health risks would be similar wherever oil and gas development is occurring.

\section{Water Contamination}

Whereas the conventional method of natural gas production utilizes about 20,000 to 80,000 gallons of fluid, the unconventional method utilizes up to 5 million gallons of fluid per hydraulic fracturing event, which includes not only water and sand, but also numerous toxic chemicals. The potential for contamination of aquifers by the residual fracking fluids that remain underground must be considered. The likelihood of spills throughout the entire lifecycle of development also must be taken into account. Blowouts (uncontrolled release of natural gas from a gas well after pressure control systems have failed) allow gas and/or highly contaminated produced waters to flow to the surface; hoses come undone, gaskets fail, pits or tanks that hold the fracking fluids leak raising the serious risk of ground and water contamination. Even small quantities of the toxic fracking fluids can contaminate shallow aquifers with hydrocarbons, toxic chemicals, heavy metals, and radioactive materials.

Further, improper wastewater disposal, specifically the handling of fracking fluids including flowback wastewater (a byproduct of the process), can lead to contamination of ground and water [21]. The flowback can be taken to sewage plants, but it is widely acknowledged that sewage plants are not equipped to handle the contaminants. There have been reports of untreated wastewater being dumped into rivers and streams and sprayed on rural roads and forests [22].

The New York Times, in its analysis of more than 30,000 pages of federal, state, and company records relating to more than 200 gas wells, found that radioactive wastewater from the process has been discharged into rivers that supply drinking water to millions of people in Pennsylvania and Maryland. At least 12 sewage treatment plants in three states have discharged waste that was only partly treated into rivers, lakes, and streams [23]. There have been wellpublicized instances of water contamination in Pavillion, WY, and Dimock, PA [24, 25], and gas has seeped into underground drinking water supplies in five states (Colorado, Ohio, Pennsylvania, Texas, and West Virginia). Further, a study conducted in Northeastern Pennsylvania found that water wells near a fracking site were 17 times more likely to exhibit methane contamination than wells not near drilling sites [26].

\section{Air and Soil Contamination}

Unconventional natural gas development causes air pollution from multiple sources. Many particulates and chemicals are released into the atmosphere, including sulfuric oxide, nitrogen oxides, volatile organic compounds (VOCs), benzene, toluene, diesel fuel, hydrogen sulfide, and radon gas, all of which can have serious health implications. Further, the venting or flaring of wells during drilling and production contributes to local air pollution.

The drilling sludge, which is brought to the surface during the drilling process, contains fracking fluid, drilling mud, and radioactive material from the subsurface land formation, hydrocarbons, metals, and volatile organic compounds. Sludge, often left to dry on the surface in waste pits, may be removed to waste disposal sites (but not always to hazardous waste sites) or may be tilled into the soil in "land farms." These practices raise the risk of contaminating soil, air, and surface water, as a result of the fine dust becoming airborne thus affecting local air quality and raising the risk of respiratory disease. Based on concerns about the exposure to dust containing silica sand, the US Occupational Safety and Health Administration, along with the National Institute of Occupations Safety and Health (NIOSH), released a joint hazard alert on fracking silica in June, 2013 [27].

Unconventional natural gas development requires many diesel trucks for the transportation of the products used in drilling as well as the removal of flowback fluid. Diesel emissions contain nitrogen oxides and volatile organic compounds, which can react to sunlight to produce ozone, a strong respiratory irritant associated with increased respiratory morbidity and mortality [28].

\section{Conclusion}

The health impacts related to unconventional natural gas development may not be evident for years, as medical conditions with long latency periods will present over time. While the potential long-term, cumulative effects will not be known for years, we argue that it would be prudent to begin to track and monitor trends in the incidence and prevalence of diseases that already have been shown to be influenced by environmental agents. Meanwhile, the natural gas industry needs to address the risks to human and animal health and take steps to limit, preferably to eliminate, the exposure pathways. We need far greater transparency and full chemical disclosure. There needs to be an end to discharging effluent into rivers, streams, and groundwater. There needs 
to be much more attention paid to curtailing or preferably eliminating spills and leaks of radioactive wastewater. There needs to be an end to the disposal of radioactive sludge from drilling sites in landfills. There needs to be a safer way to develop this resource to limit the exposure to silica, which can cause silicosis, chronic obstructive pulmonary disease, and lung cancer. Banning the practice of burning off the initial flow of natural gas (flaring) needs to be mandated sooner than 2015, the date when EPA ruling goes into effect. And, perhaps most importantly, there needs to be a well-designed epidemiologic study conducted to empirically assess health status among those living proximate to active development compared to those living in areas where development is not occurring.

\section{Conflict of Interests}

No author has any conflict of interests or financial conflicts to declare.

\section{Acknowledgment}

The authors would like to acknowledge Nitin Kondamudi for his initial research efforts and help in the preparation of this paper.

\section{References}

[1] D. J. Soeder and W. M. Kappel, "Water resources and natural gas production from the Marcellus Shale," U.S. Department of the Interior, U.S. Geological Survey Fact Sheet 2009-3032, 2009.

[2] Environmental Protection Agency (EPA), "Evaluation Impacts to Underground Sources of Drinking Water by Hydraulic Fracturing of Coalbed Methane Reservoirs," June 2004, http://www.epa.gov/ogwdw/uic/pdfs/cbmstudy_attach_uic_ ch04_hyd_frac_fluids.pdf.

[3] I. Urbana, Regulation Lax as Gas Wells' Tainted Water Hits Rivers, New York Times, New York, NY, USA, 2011.

[4] National Research Council, Pesticides in the Diets of Infants and Children, National Academies Press, Washington, DC, USA, 1993.

[5] R. Barouki, P. D. Gluckman, P. Grandjean, M. Hanson, and J. J. Heindel, "Developmental origins of non-communicable disease: implications for research and Public Health," Environmental Health, vol. 11, pp. 42-51, 2012.

[6] P. J. Landrigan, C. B. Schechter, J. M. Lipton, M. C. Fahs, and J. Schwartz, "Environmental pollutants and disease in American children: estimates of morbidity, mortality, and costs for lead poisoning, asthma, cancer, and developmental disabilities," Environmental Health Perspectives, vol. 110, no. 7, pp. 721-728, 2002.

[7] K. W. Whitworth, E. Symanski, and A. L. Coker, "Childhood lymphohematopoietic cancer incidence and hazardous air pollutants in Southeast Texas, 1995-2004," Environmental Health Perspectives, vol. 116, no. 11, pp. 1576-1580, 2008.

[8] P. J. Lupo, E. Symanski, D. Kim Waller et al., "Maternal exposure to ambient levels of Benzene and Neural tube defects among offspring: Texas, 1999-2004," Environmental Health Perspectives, vol. 119, no. 3, pp. 397-402, 2011.
[9] R. Slama, O. Thiebaugeorges, V. Goua et al., "Maternal personal exposure to airborne benzene and intrauterine growth, Environmental Health Perspectives, vol. 117, no. 8, pp. 1313-1321, 2009.

[10] R. Barouki, P. D. Gluckman, P. Grandjean, M. Hanson, and J. J. Heindel, "Developmental origins of non-communicable disease: implications for research and public health," Environmental Health, vol. 11, pp. 42-51, 2012.

[11] L. Trasande and Y. Liu, "Reducing the staggering costs of environmental disease in children, estimated at $\$ 76.6$ billion in 2008," Health Affairs, vol. 30, pp. 863-870, 2011.

[12] R. J. Landrigan and L. R. Goldman, "Children's vulnerability to toxic chemicals: a challenge and opportunity to strengthen health and environmental policy," Health Affairs, vol. 30, pp. 842-850, 2011.

[13] February 2013, http://www.marcellusgas.org/.

[14] PennEnvironment Research \& Policy Center, "In the Shadow of the Marcellus Boom," Tech. Rep., May 2011, http://www .pennenvironment.org/reports/pae/shadow-marcellus-boom.

[15] R. L. Kosnik, “The oil and gas industry's exclusions and exemptions to major environmental statutes. Oil and gas accountability project," Tech. Rep., 2007, http://www.ogap.org/.

[16] T. Colborn, C. Kwiatkowski, K. Schultz, and M. Bachran, "Natural gas operations from a public health perspective," Human and Ecological Risk Assessment, pp. 17-15, 2011.

[17] T. Colburn, Spreadsheet of Products, Chemicals and Their Health Effects, The Endocrine Disruption Exchange, Paonia, Colo, USA, 2013, http://www.endocrinedisruption.org/chemicals .multistate.php.

[18] M. Jerrett, R. T. Burnett, C. Arden Pope et al., "Long-term ozone exposure and mortality," New England Journal of Medicine, vol. 360, no. 11, pp. 1085-1095, 2009.

[19] R. Witter, K. Stinson, H. Sackett et al., "Potential exposurerelated human health effects of oil and gas development," A White Paper, 2008, http://docs.nrdc.org/health/files/hea 08091702A.pdf.

[20] L. M. McKenzie, R. Z. Witter, L. S. Newman, and J. L. Adgate, "Human health risk assessment of air emissions from development of unconventional natural gas resources," Science of the Total Environment, vol. 424, pp. 79-87, 2012.

[21] D. J. Rozell and S. J. Reaven, "Water pollution risk associated with natural gas extraction from the Marcellus Shale," Risk Analysis, vol. 32, no. 8, pp. 1382-1393, 2011.

[22] R. Hammer and J. VanBriesen, "In fracking's wake: new rules are needed to protect our health and environment from contaminated wastewater," Tech. Rep., NRDC, Washington, DC, USA, 2012, http://www.nrdc.org/energy/files/FrackingWastewater-FullReport.pdf.

[23] I. Urbana, Regulation Lax as Gas Wells' Tainted Water Hits Rivers, New York Times, New York, NY, USA, 2011.

[24] EPA, "EPA Releases Draft Findings of Pavillion, Wyoming Ground Water Investigation for Public Comment and Independent Scientific Review," 2011, http://yosemite.epa.gov/ opa/admpress.nsf/0/EF35BD26A80D6CE3852579600065C $94 \mathrm{E}$.

[25] K. Sinding, "Is Dimock's Water Really Safe? One Federal Health Agency Is Not so Sure," Natural Resources Defense Council (NRDC): Switchboard. September 2012, http://switchboard.nrdc.org/blogs/ksinding/is_dimocks_water_really_safe_o .html.

[26] S. G. Osborn, A. Vengosh, N. R. Warner, and R. B. Jackson, "Methane contamination of drinking water accompanying 
gas-well drilling and hydraulic fracturing," Proceedings of the National Academy of Sciences of the United States of America, vol. 108, no. 20, pp. 8172-8176, 2011.

[27] Occupational Safety \& Health Administration (OSHA) and the National Institute for Occupational Safety and Health (NIOSH), "Worker Exposure to Silica During Hydraulic Fracturing," United States Department of Labor, February 2013, http://www.osha.gov/dts/hazardalerts/hydraulic_frac_hazard alert.html.

[28] M. Jerrett, R. T. Burnett, C. Arden Pope et al., "Long-term ozone exposure and mortality," New England Journal of Medicine, vol. 360, no. 11, pp. 1085-1095, 2009. 


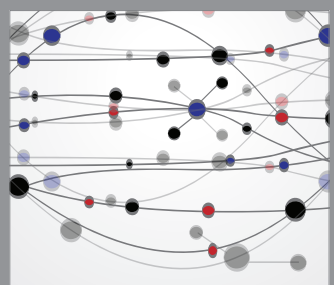

The Scientific World Journal
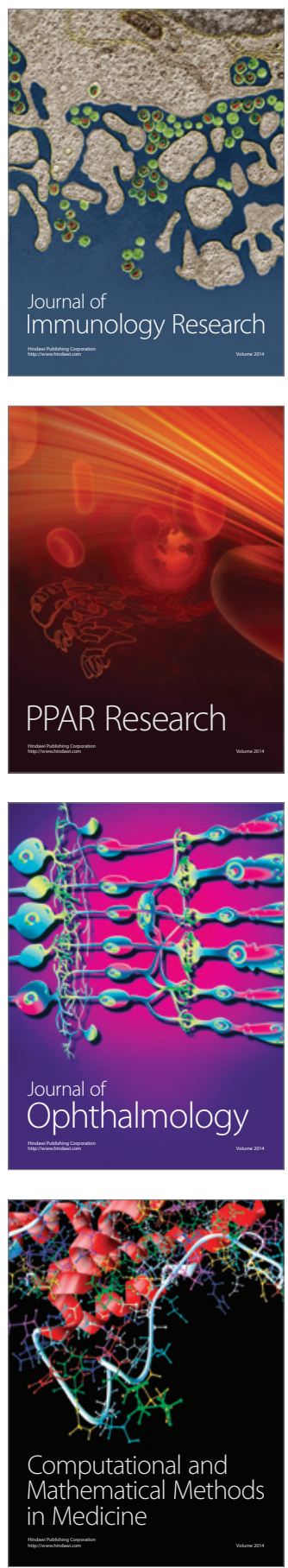

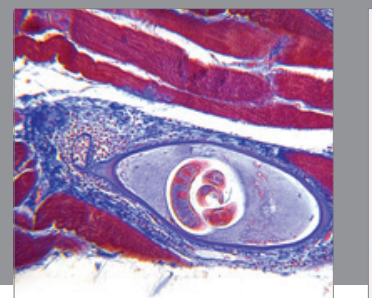

Gastroenterology

Research and Practice
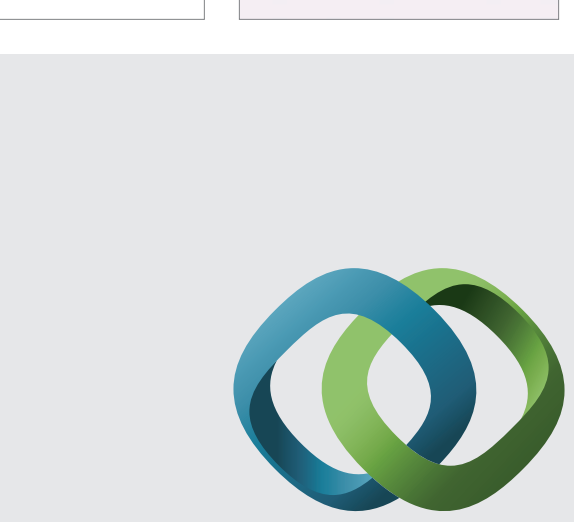

\section{Hindawi}

Submit your manuscripts at

http://www.hindawi.com
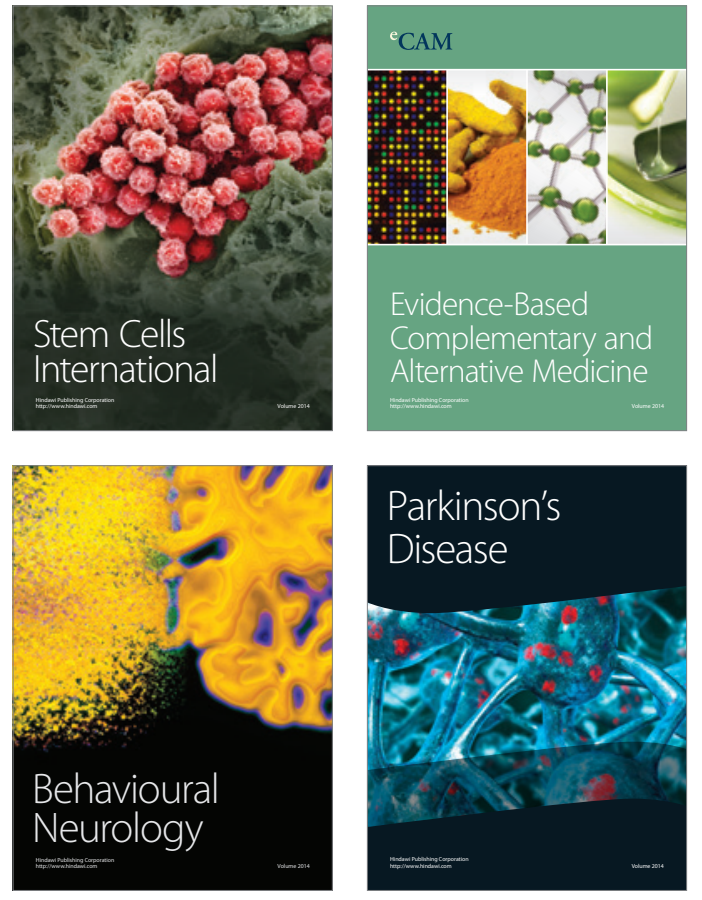
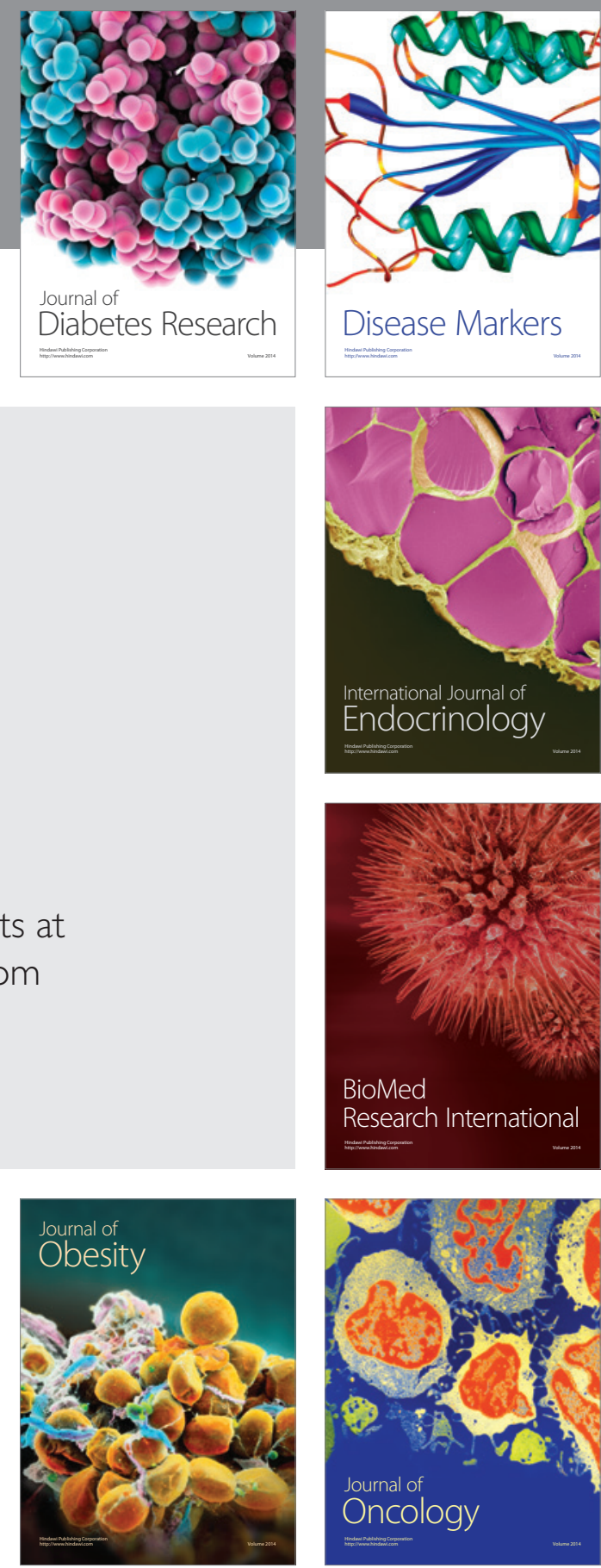

Disease Markers
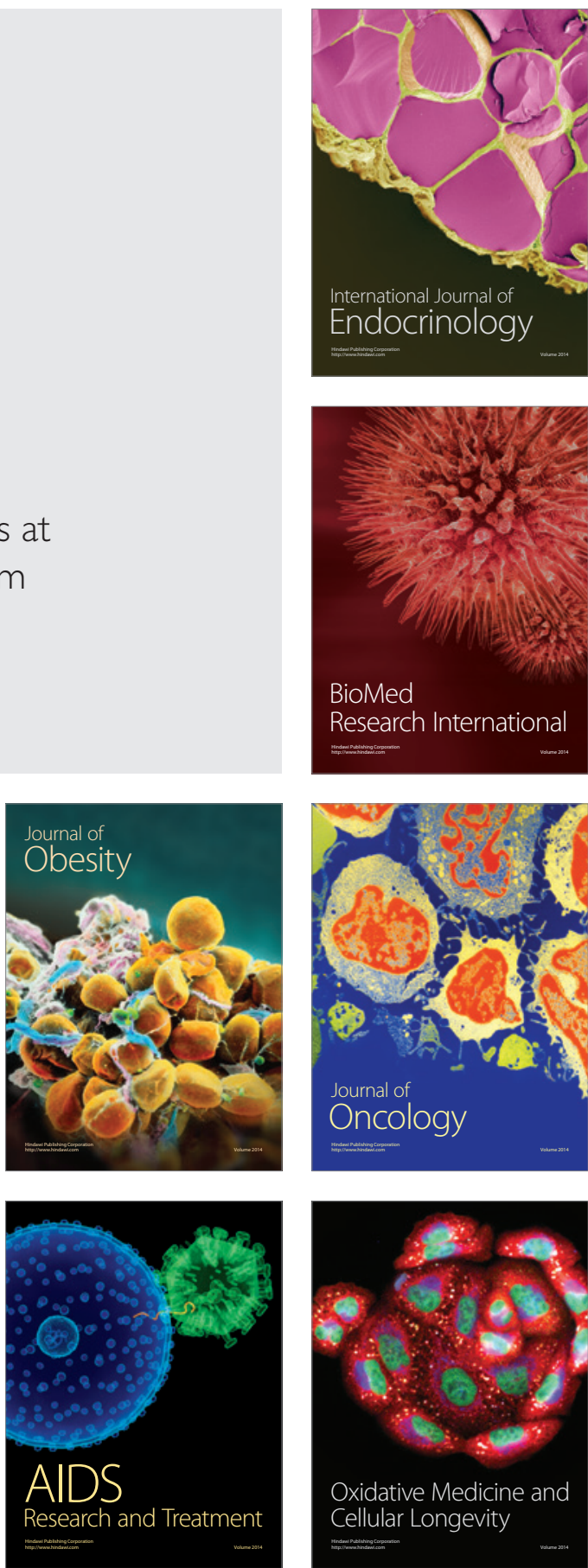